
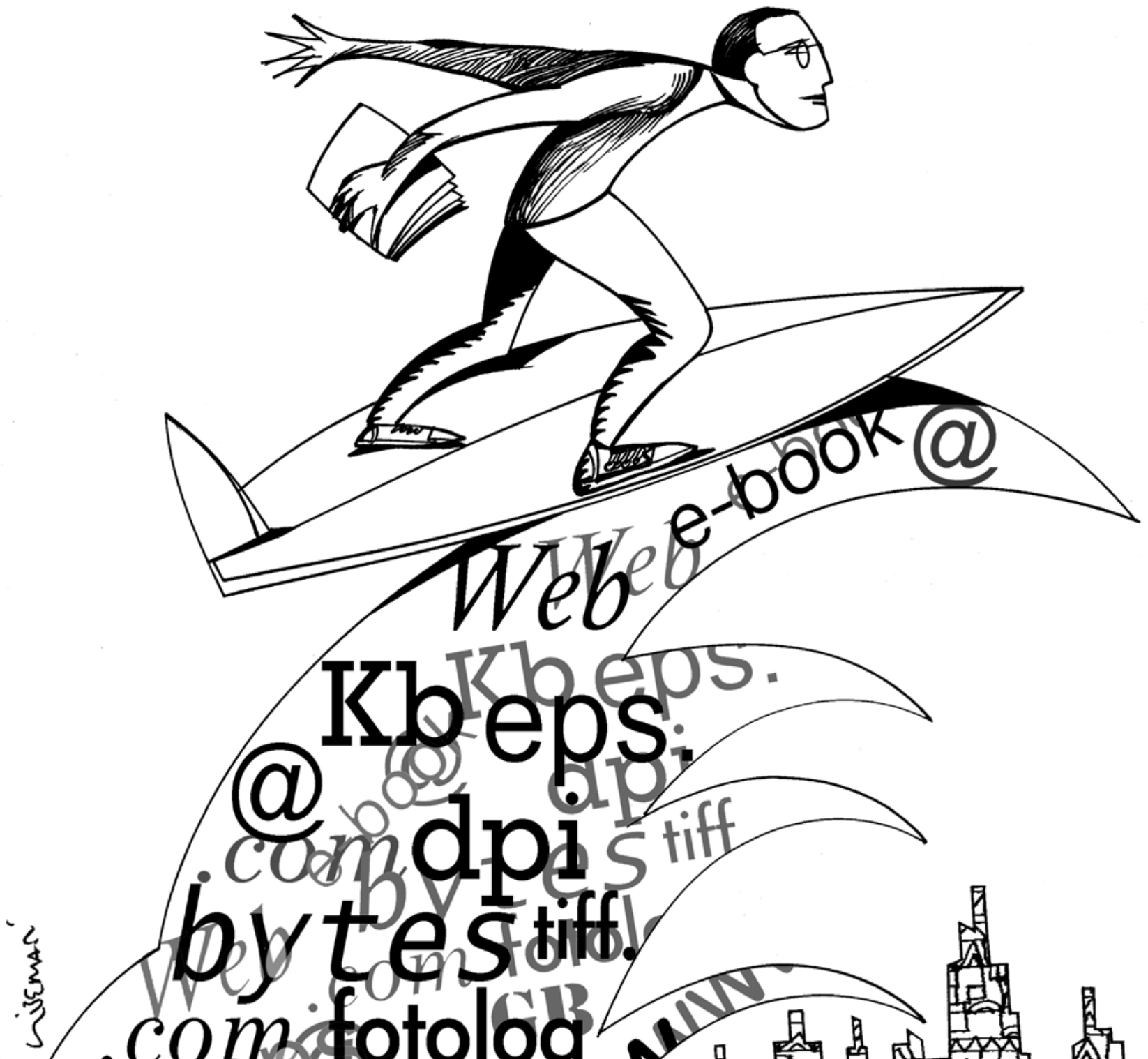


\title{
SURFANDO NA Sociedade DA INFORMAÇÃO E DO CONHECIMENTO: A Questão das Competências Docentes
}

\author{
Mirian Maia do Amaral* \\ Lúcia Regina Goulart Vilarinho ${ }^{* *}$
}

\begin{abstract}
Resumo
$\mathrm{O}$ artigo ressalta o desafio de se educar na cibercultura, quando os alunos constituem o centro da ação educativa e o professor, uma das muitas fontes de informação a que eles recorrem. Este professor, para responder às demandas educacionais, precisa atualizar-se constantemente, o que implica domínio de um conjunto de saberes/ competências necessários ao exercício da docência, de modo a garantir uma atuação proficiente, capaz de enfrentar os desafios impostos por uma sociedade marcada pela incerteza, instantaneidade e rapidez das mudanças. Decorre daí a necessidade de se identificar e mapear as competências docentes, cujo repertório deve estar sintonizado com o contexto e as estratégias da instituição onde esse ator exerce suas atividades.
\end{abstract}

Palavras-chave: Sociedade da informação; Cibercultura; Competências docentes; Interação professor-aluno.

\section{CONSIDERAÇÕES INICIAIS}

O desenvolvimento das Tecnologias de Informação e Comunicação (TIC) tem acarretado aceleradas mudanças, que incidem nas atividades econômicas, sociais, culturais, políticas e, em especial, no mercado e nas rotinas de trabalho. Uma melhor compreensão dessas mudanças exige voltar no tempo e considerar a evolução da organização social humana: seus movimentos e deslocamentos.

Lévy ${ }^{1}$ afirma que a revolução contemporânea das comunicações teve sua origem com o aparecimento do homem na face da Terra e sua lenta, mas crescente, dispersão por outras regiões, impulsionada pelo aumento da população, resultando em separação e distanciamento. A segunda grande mudança, destacada por este autor, denominada neolítica, foi marcada por um período de considerável desenvolvimento, dado o surgimento da agricultura, do Estado, da cidade e da escrita. Finalmente, a terceira grande

\footnotetext{
* Mestre em Educação pela Universidade Estácio de Sá; pedagoga e especialista em Administração e Recursos Humanos; professora dos cursos de pós-graduação (MBA) da Fundação Getulio Vargas.E-mail:amaral@fgr.br.

** Doutora em Educação pela Universidade Federal do Rio de Janeiro; professora dos cursos de mestrado em Educação e Direito da Universidade Estácio de Sá. E-mail: Igvilarinho@, netbotanic.com.br.
}

Recebido para publicação em: 26/02/08. mudança - propiciada pela intensificação das comunicações teve início no século XV, com as grandes navegações, passou pela revolução industrial e chegou até os nossos dias.

A atual conjuntura - caracterizada pela globalização de mercados e pela emersão do ciberespaço - impõe um quadro de individualismo, competitividade, falta de tempo e volatilidade nas relações, além de gerar um ritmo frenético de produção e consumo, que ressalta o utilitarismo, banaliza princípios filosóficos, sociológicos e, por que não dizer, éticos. $\mathrm{Na}$ ótica de Soares $^{2}$, tempo, qualidade e qualificação ganham destaque como indicadores de produtividade no mundo do trabalho, significando uma nova maneira de fazer e de ser profissional.

Nesse cenário, o conceito de competência vem sendo objeto de discussão, dando origem a inúmeras interpretações, tanto na área da educação como nas organizações em geral. Apesar das diferentes nuances que vem tomando, pode-se perceber certa complementaridade de idéias, pois, em essência, esses conceitos comportam os pilares Conhecimentos, Habilidades e Atitudes (CHA). Dada à velocidade com que, hoje, as competências desaparecem, transformam-se e se renovam, torna-se relevante discutir o papel do professor no desenvolvimento de suas atividades profissionais, seja em ambientes de aprendizagem virtuais, semipresenciais ou presenciais.

Assim, este artigo objetiva ressaltar o desafio de se educar na sociedade da informação e do conhecimento, a qual requer um indivíduo que acompanhe as mudanças tecnológicas e tenha, 
sobretudo, capacidade de se adaptar e inovar, a fim de garantir seu espaço de liberdade e autonomia, de modo a poder responder aos desafios da contemporaneidade.

Nessa direção, enfatiza-se a importância de se identificar e mapear as competências necessárias à atuação do professor, no ambiente em que exerce suas atividades, em consonância às finalidades e estratégias organizacionais. Cabe dizer que, no presente texto, o termo competência é definido como "um saber agir responsável e reconbecido, que implica mobilizar, integrar, transferir conhecimentos, recursos e habilidades, agregando valor econômico para a organização e valor social para o indivíduo" (FLEURY; FLEURY). ${ }^{3}$

\section{A PRESENÇA DA TECNOLOGIA E SUAS IMPLICAÇõES}

A globalização, entendida, de uma forma abrangente, como 'a tomada de consciência do mundo', é caracterizada pela abertura de mercados e constitui processo irreversível. Esse fenômeno, sustentado pela revolução tecnológica, aproximou povos e nações antes dispersos, na direção de uma sociedade planetária, onde todos estão interconectados: homem, terra, universo.

Nesse contexto, não restam dúvidas quanto ao relevante papel exercido pelas TIC no desenvolvimento sociopolítico e econômico dos países e na integração de diferentes povos. No entanto, deve-se considerar o fato de que, se por um lado, as TIC têm contribuído para o bem-estar da humanidade, possibilitando que as pessoas mediante o acesso a uma rede de interconexões, comprem, vendam e troquem informações e serviços livremente, por outro, vêm acentuando as disparidades entre nações desenvolvidas e não desenvolvidas, aumentando desigualdades e ampliando o contingente de excluídos sociais e digitais.

Fomentando outros vínculos sociais entre pessoas, grupos e nações, as TIC alteram conceitos de tempo e espaço e, através do ciberespaço - meio que emerge da rede mundial de computadores (web)-, ganham uma dimensão socioplanetária, abrigando um conjunto de seres humanos com suas informações, conhecimentos, valores, costumes, pensamentos, que navegam e alimentam esse

pessoas observadoras, reflexivas, criativas, com capacidade de buscar informaçôes relevantes e transformá-las em conbecimento são imprescindiveis no mundo do trabalbo e na ótica da
sociedade, em geral.

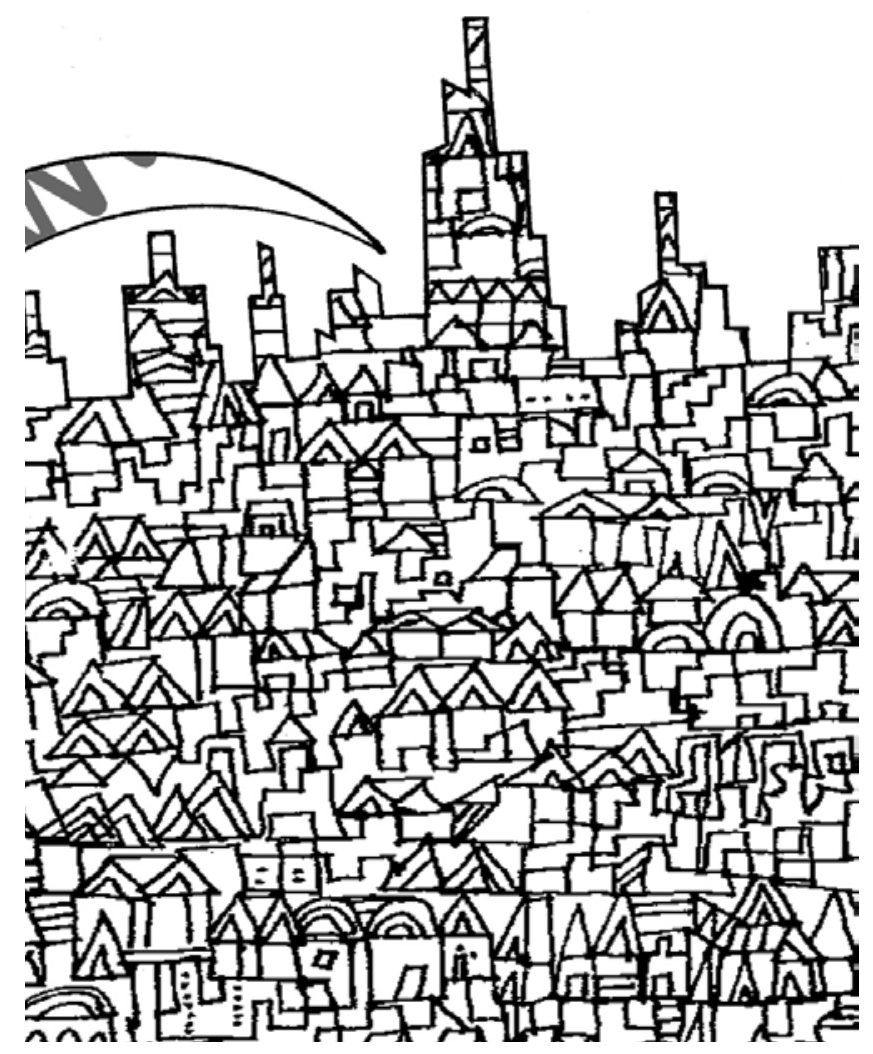

universo, fazendo florescer uma nova cultura - a cibercultura.

Para Quéau ${ }^{4}$, a cibercultura não é simplesmente uma cultura do ciberespaço e da navegação pelos imensos recursos da informação; é algo mais profundo que uma revolução técnica, que exige um novo olhar para o mundo, uma nova abordagem dos problemas e a busca de soluções. Envolve uma perspectiva planetária,na medida em que reúne o global e o local - trata-se de uma cultura 'glocal'.

No bojo da relação dialética desses dois fenômenos (globalização e cibercultura), verifica-se a hegemonia do capital financeiro, a interdependência das economias nacionais e uma valorização exacerbada das novas tecnologias, o que resulta em mecanismos perversos de desqualificação de uma quantidade considerável de mão-de-obra, julgada inapta para dar conta das exigências do mercado de trabalho.

Apesar de todas as críticas recebidas nas décadas de 1970 e 1980, a teoria do capital humano (SCHULTZ) 5 trouxe à tona a importância do conhecimento individual, visto como recurso indispensável ao desenvolvimento das sociedades, e que demanda contínua renovação em face das mudanças que ocorrem na realidade. Hoje, mais do que nunca, grande parte dos conhecimentos, habilidades, valores e atitudes adquiridos por uma pessoa no início de sua trajetória profissional tornam-se obsoletos antes mesmo do final de suas atividades. Nesse contexto, pessoas observadoras, reflexivas, criativas, com capacidade de buscar informações relevantes e transformá-las em conhecimento são imprescindíveis no mundo do trabalho e na ótica da sociedade, em geral.

Já na década de 1960, MacLuhan apontava as das TIC, alertan- 
do para a importância do usuário se engajar neste processo.

[...] Ninguém informa ninguém; o indivíduo informa-se. O processo de compreender, persuadir, ensinar não depende das habilidades do "agente", mas da atividade do "paciente". [...] Não basta, como supõem os devotos da comunicação de massa, saturar o ambiente de informação: se o aluno não estiver mobilizado para recebê-la é como se a informação não existisse. ${ }^{6}$

Assim, além do acessar a informação, compreendê-la, qualificá-la, aplicá-la a contextos variados e disponibilizá-la, são competências requeridas na contemporaneidade. Trabalhar equivale, cada vez mais, a aprender, transmitir e produzir saberes.

Em um cenário onde se dinamizam competências, o conhecimento adere ao fluxo das mudanças e, conseqüentemente, passa a exigir dos indivíduos atualização constante, de modo que estes possam corrigir possíveis deficiências em sua formação básica, ou mesmo desenvolver a capacidade de pensar, sentir e agir, na busca de soluções para os problemas do cotidiano. Essa tendência de valorização de competências alinhada ao fluxo das mudanças coloca em destaque a educação continuada, levando-a a assumir diferentes conotações, como por exemplo: participação em seminários, congressos, conferências ou ciclos de debates; leituras de trabalhos publicados em anais, livros e periódicos especializados nacionais e estrangeiros; cursos diversos; estudos individuais e em grupos; visitas técnicas; conversas informais para troca de experiências; participação em grupos de discussão, entre outros.

Referindo-se à formação continuada de professores, Santos situa as diferentes formas assumidas por esse processo:

[...] é possível identificar tanto as iniciativas pessoais quanto as institucionais, podendo ambas ser individuais ou coletivas. Como exemplo de iniciativa pessoal de caráter individual, teríamos o caso do ingresso em cursos de especialização ou congêneres, escolhidos pelo próprio professor, realizados em horários diferentes do seu horário de trabalho e de sua responsabilidade exclusiva. Como exemplo da iniciativa pessoal de caráter coletivo, podemos citar alguns tipos de atividades que começam a proliferar em que grupos de quatro a oito professores pagam a um profissional para lhes dar uma assessoria técnica geralmente voltada para aspectos psicopedagógicos, com o objetivo de ajudá-los a resolver seus problemas de sala de aula. ${ }^{7}$

A autora argumenta ainda que a formação continuada deve levar o profissional a refletir e assumir sua responsabilidade pedagógica e social, possibilitando-lhe adquirir uma visão mais ampla e crítica da educação.

Apesar de reconhecer a importância dessa formação, contemplada inclusive na LDB - Lei 9394/96, Falsarella ${ }^{8}$ admite que muitos programas oferecidos por sistemas de ensino carecem de maior atenção, tendo em vista se tornarem mais significativos para os professores. Segundo esta autora, a educação continuada constitui processo a ser desenvolvido no dia-a-dia do trabalho, de forma contínua, possibilitando aos profissionais participarem ativamente do mundo que os rodeia, ao mesmo tempo em que incorporam a vivência ao conjunto dos saberes de sua profissão.

Nóvoa $^{9}$ ressalta que a formação docente deve ser sustentada

\section{a formação docente deve ser \\ sustentada por uma reflexão \\ crítica permanente sobre a \\ (re)construção da identidade \\ profissional, o que acontece \\ no processo de integração \\ do sujeito com seu trabalho \\ cotidiano.}

por uma reflexão crítica permanente sobre a (re)construção da identidade profissional, o que acontece no processo de integração do sujeito com seu trabalho cotidiano. Dessa forma, o profissional não fica amarrado à construção do conhecimento exclusivamente pela via do acúmulo de cursos ou domínio instrumental de estratégias de ação.

Ao partilhar dessa opinião, Porto $^{10}$ afirma que no processo educativo existem duas tendências para a formação dos indivíduos: a estruturante e a interativo-construtivista. A primeira, mais tradicional, tem um caráter comportamental-tecnicista, caracterizando-se basicamente pela definição antecipada de conteúdos, programas e procedimentos. A segunda, mais atual, consiste na formação em serviço, com base na reflexão, na crítica e na investigação, voltada para os "contextos educativos e dos sujeitos a quem se destina" (PORTO). ${ }^{11}$

Com base no pensamento de Dewey ${ }^{12}$, que contrapõe a prática reflexiva à rotina, fundamentada no impulso, na tradição e na autoridade, inibindo o questionamento e favorecendo a aceitação acrítica da realidade, Schön ${ }^{13}$ defende o desenvolvimento de uma prática reflexiva para a formação de um profissional, tendo como base três idéias centrais: o conhecimento na prática, a reflexão da prática e a reflexão sobre a prática.

O conhecimento na prática, segundo o autor, consiste no conhecimento tático, direcionado a soluções de problemas; este se manifesta espontaneamente e se expressa na execução de uma dada tarefa, sem necessidade de reflexão prévia. A reflexão da prática representa o saber fazer; e a reflexão sobre a prática corresponde ao saber compreender. Esses processos de pensamentos distintos não acontecem simultaneamente, mas se completam na qualidade reflexiva do profissional. Nessa perspectiva, a formação em serviço possibilita, estabelecer o ciclo fazer-refletir-depurar. Responder aos desafios da sociedade do conhecimento, portanto, requer reflexão sobre a prática profissional e atualização constante dos indivíduos, que devem estar 


\section{a aprendizagem torna-se um valioso instrumento a serviço do trabalhador, no processo de criação e inovação, e não se restringe aos sistemas escolares; tampouco, é privilégio dos sistemas formais de ensino. Ela perpassa toda a trajetória de vida e acontece em qualquer espaço; inclusive no ambiente de trabalbo.}

conectados às exigências do mercado de trabalho.

A sociedade do conhecimento é uma sociedade de aprendizagem. O sucesso econômico e uma cultura de inovação contínua dependem da capacidade dos trabalhadores de se manter aprendendo acerca de si próprio e uns com os outros. Uma economia do conhecimento não funciona a partir da força das máquinas, mas a partir da força do cérebro, do poder de pensar, aprender e inovar (HARGREAVES). ${ }^{14}$

Dessa forma, a aprendizagem torna-se um valioso instrumento a serviço do trabalhador, no processo de criação e inovação, e não se restringe aos sistemas escolares; tampouco, é privilégio dos sistemas formais de ensino. Ela perpassa toda a trajetória de vida e acontece em qualquer espaço; inclusive no ambiente de trabalho.

Para Meister ${ }^{15}$, as empresas/organizações estão se transformando em verdadeiros laboratórios de aprendizagem, onde se aplicam e experimentam novas tecnologias e se adotam teorias de aprendizagem que estimulam o trabalhador. Essas são organizações que aprendem que seu diferencial competitivo está na capacidade de se reinventar a cada dia, e que isso só se torna possível se suas ações educacionais alcançarem todos os níveis, compartilhando e disseminando o conhecimento.

As pessoas expandem continuamente sua capacidade de criar os resultados que realmente desejam, onde se estimulam padrões de pensamento novos e abrangentes, a aspiração coletiva ganha liberdade e onde as pessoas aprendem continuamente a aprender juntas (SENGE). ${ }^{16}$

Com o aumento das exigências em relação à capacidade do trabalhador de empreender, criar e aplicar, no exercício de suas atividades, métodos e ferramentas que possibilitem a racionalização e a melhoria da produção e dos serviços, a vida organizacional vai, paulatinamente, rivalizando-se com o ambiente educacional formal. É nesse espaço, onde eventos não previsíveis ocorrem a todo instante, que a aprendizagem vai acontecer de forma acelerada. Assim, a formação em serviço, ligada às estratégias institucionais, ganha relevo e, ao tomar emprestado subsídios relevantes retirados da literatura pertinente, traz para o seu interior uma visão de competência humana e organizacional, capaz de alavancar resultados. No dizer de Bonilauri,

[...] os métodos, as práticas e as ações não terão valor se não estiverem claramente comprometidos com o entendimento incondicional do segmento e do negócio da organização que a abriga. [...] Mesmo que esteja disponível o melhor contingente de profissionais para ser absorvido pelas empresas, sempre haverá a possibilidade (e a necessidade) de seu aprimoramento e capacitação. Desse modo, seja para a própria empresa, seja para o mercado de trabalho, empresa e escola têm papéis complementares e sinérgicos na preparação das pessoas. ${ }^{17}$

Um olhar mais atento para o mercado de trabalho coloca em evidência quatro tendências: (a) preocupação dos profissionais com o autodesenvolvimento e com a empregabilidade; (b) incorporação crescente do uso da internet na realização dos negócios empresariais e nas instituições em geral; (c) competitividade cada vez maior, exigindo de seus profissionais o domínio de competências que lhes possibilitem o exercício de suas funções e da cidadania; e, por último, (d) necessidade de a educação se redefinir, claramente, a fim de atender às demandas da contemporaneidade. Diante dessas tendências, cresce a responsabilidade da escola e dos atores educacionais, na busca de um diálogo com essas demandas.

\section{A escola e os atores educacionais: REDEFININDO SEUS PAPÉIS}

Devido ao esvaziamento do papel da família como instituição social e ao aumento das exigências da sociedade em relação à escola no sentido de conduzir o aluno do estado 'não educado' para o de 'educado', a educação acabou trazendo para si responsabilidades e deveres inerentes à dinâmica familiar e social, incorporando atribuições educativas que até pouco tempo não eram da alçada dos profissionais de ensino.

Paralelamente, o crescimento da demanda por capacitação e aperfeiçoamento de pessoal para responder à complexidade das novas situações e equipamentos, num mercado em franca expansão, tem levado a educação a ser percebida como o setor da sociedade capaz de corrigir os desvios da marginalidade produzida pelo desemprego. Nessa perspectiva, a educação, mais especificamente a escolarização, tem sido apontada como responsável pela integração social do indivíduo, passível de promover a flexibilização das práticas profissionais e de garantir a adaptação aos novos tempos (SOARES). ${ }^{18}$

Essa amplitude de tarefas demanda à escola reaproximar-se da família a fim de redefinir seu papel, deixando bem claras suas competências e obrigações. Como uma organização de aprendizagem, deve transformar-se num sistema pensante e flexível, aberto em relação a si mesmo e ao seu entorno, estimulando o processo de participação democrática da comunidade, mediante discussão de seu projeto político-pedagógico - o que significa incluir os sujeitos da educação no cotidiano escolar, sem deixar 
de exercer seu poder de decisão no que tange aos processos administrativos e pedagógicos.

$\mathrm{Na}$ reorganização de seu trabalho é fundamental, ainda, que valorize os atores educacionais, abra espaço para a pesquisa e se transforme em comunidade de aprendizagem, onde se produz conhecimento sobre educação. Isso implica compreender o aluno dos dias atuais - a chamada geração net ${ }^{9}$, para quem o acesso à informação é feito de maneira mais interativa e menos seqüencial, a partir de fontes diversas, dado que seu pensamento não é linear, pois privilegia a hipertextualidade. Para esse aluno, a escola deve ser provedora da informação qualificada, significativa e multimídia; nela, a pedagogia da transmissão perde sua força, cedendo espaço aos processos de cooperação, colaboração, interatividade e dialogicidade, tendo em vista a construção do conhecimento. Em outras palavras, educar na sociedade informacional,

significa muito mais que treinar as pessoas para o uso das Tecnologias de Informação e Comunicação: trata-se de investir na criação de competências suficientemente amplas, que lhes permitam terem uma atuação efetiva na produção de bens e serviços, tomar decisões fundamentadas no conhecimento, ope-

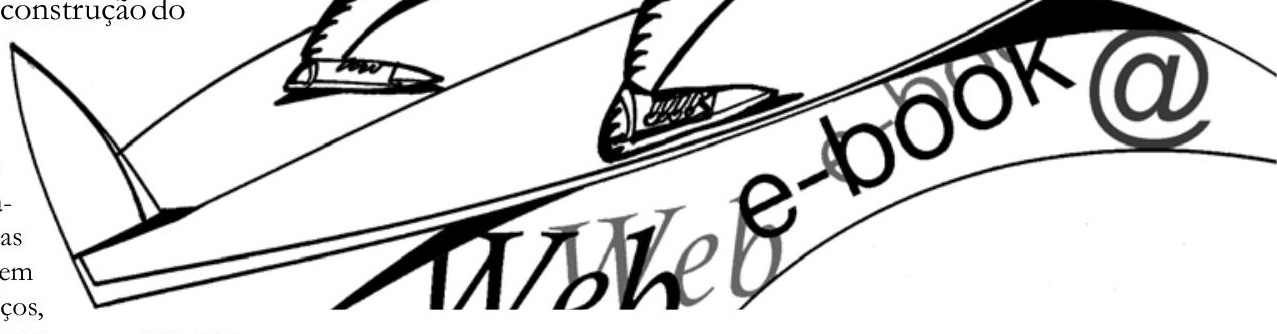
fluência os novos meios e ferramentas no seu trabalho, [...] formar os indivíduos para 'aprender a aprender', de modo a serem capazes de lidar positivamente com a contínua e acelerada transformação da base tecnológica (TAKAHASHI). ${ }^{20}$

Silva ${ }^{21}$ alerta que o professor, acostumado ao primado da transmissão na educação e na mídia de massa, tem agora o desafio de educar na cibercultura, o que requer desenvolver sua imaginação criadora para atender às demandas da aprendizagem interativa. Isso implica investimento educacional desde a

\section{A rapidez com que os} conbecimentos evoluem, aliada às mudanças requeridas pela sociedade, exigem do professor contemporâneo uma aprendizagem permanente individual e colaborativa, o que se traduz em desenvolvimento de novas competências e reconfiguração de outras. formação básica, estendendo-se, como um continuum, ao longo de sua vida profissional; ou seja, uma educação continuada, que propicie o desenvolvimento de competências para atuar num mundo marcado por mudanças e incertezas.

Esse contexto requer docentes que: (a) estimulem no aluno a busca do seu próprio conhecimento, a interação, a produção coletiva e o relacionamento com o outro; (b) proponham atividades que os habilitem para o uso das Tecnologias de Comunicação e Informação; (c) conheçam os fundamentos da disciplina que ensinam e sejam sensíveis à realidade em que atuam; enfim, (d) se prepararem para a vida e não para as circunstâncias do momento (CÁCERES). ${ }^{22}$

Sintonizado com os novos tempos, o professor percebe que não detém o monopólio do saber, que pode ser acessado em fontes de consulta variadas. Ele compreende, principalmente, que a comunicação, para ser eficaz, tem de ser resultante da produção conjunta docente/discentes, num processo de coautoria, com espaço para uma ampla liberdade de associações e significações. Nesse contexto, sua função é a de formulador de problemas, provocador, questionador, coordenador de equipes, arquiteto de percursos e experiências, disponibilizando para os alunos informações diversas, facilitando permutas, promovendo o diálogo entre culturas. Tudo isso requer redimensionar a prática docente presencial e/ou online, de modo que o professor assuma outra forma de ser docente e, conseqüentemente, atenda às demandas de um novo tipo de aluno (SILVA). ${ }^{23}$

A rapidez com que os conhecimentos evoluem, aliada às mudanças requeridas pela sociedade, exigem do professor contemporâneo uma aprendizagem permanente individual e colaborativa, o que se traduz em desenvolvimento de novas competências e reconfiguração de outras. 


\section{SABERES E COMPETÊNCIAS DO PROFESSOR: ABORDAGENS TEÓRICAS}

Competência pode ser entendida como a capacidade de o indivíduo mobilizar seus saberes para atuar, em qualquer situação. Isso pressupõe, além do saber-saber, o saber-fazer e o saber-ser. Compreender a si próprio, os outros e o mundo que o cerca, bem como suas inter-relações, possibilita lidar com as mudanças e desenvolver um processo de permanente interação, contextualização e colaboração: trata-se de estar aberto à aprendizagem.

Nóvoa ${ }^{24}$ ressalta que a construção da identidade docente se fundamenta em 'três A': na adesão a princípios, valores e projetos coletivos; na autonomia de julgamentos e de decisões e na autoconsciência, que lhe permite uma atitude reflexiva sobre seu fazer pedagógico. Para ele, existe um corpo de conhecimentos e técnicas, e um conjunto de normas e valores inerentes ao trabalho docente, gerados no contexto socioeconômico em que o sujeito exerce sua profissão, e que evolui historicamente. Assim, a identidade docente "é um lugar de lutas e conflitos, é um espaço de construção de maneiras de ser e de estar na profissão" (NÓVOA). ${ }^{25}$

Por sua vez, Perrenoud, cujas idéias sobre a docência emergem em 1980, apresenta restrições aos modelos de formação de professores que, baseados na racionalidade técnica, enfatizam a especialização. Para ele, tal formação deve valorizar os conteúdos específicos, as competências e habilidades de atuação prática, de modo a se produzir um profissional reflexivo, instigador e crítico, que possibilite a busca de novos saberes, num processo de educação continuada. Suas propostas defendem o reconhecimento da responsabilidade profissional - individual e coletiva - dos professores, o que requer uma formação voltada para "um referencial de competências, que identifique os saberes e capacidades necessários" (PERRENOUD) ${ }^{26}$.

As competências propostas por este autor apontam a necessidade de um professor que: (a) adote uma abordagem filosófica em que o aluno seja o sujeito da construção do seu conhecimento; (b) dê sentido aos diferentes saberes dos alunos; (c) crie situações de aprendizagem diversificadas; (d) administre as diferenças individuais; e (e) regule os processos e percursos de sua formação.

Em pesquisa voltada para o setor terciário, ao se referir aos desafios da formação profissional no contexto da globalização econômica, de novas formas de organização da produção e do trabalho, e dos crescentes processos de democratização da sociedade, Deluiz ${ }^{27}$ desenvolve uma tipologia de competências composta por cinco grandes dimensões, que pode ser visualizada, no quadro a seguir:

\section{Tipologia das Competências}

\begin{tabular}{|c|c|}
\hline \multicolumn{2}{|l|}{ Competências } \\
\hline Intelectuais e técnicas & $\begin{array}{l}\text { Capacidade de reconhecer e definir problemas, equacionar soluções, pensar } \\
\text { estrategicamente, introduzir modificações no processo de trabalho, atuar preven- } \\
\text { tivamente, transferir e generalizar conhecimentos. }\end{array}$ \\
\hline Organizacionais ou metódicas & $\begin{array}{l}\text { Capacidade de autoplanejar-se, auto-organizar-se, estabelecer métodos próprios, } \\
\text { gerenciar seu tempo e espaço de trabalho. }\end{array}$ \\
\hline Comunicativas & $\begin{array}{l}\text { Capacidade de expressão e comunicação com seu grupo, superiores hierárquicos } \\
\text { ou subordinados, de cooperação, trabalho em equipe, diálogo, exercício da nego- } \\
\text { ciação e de comunicação interpessoal. }\end{array}$ \\
\hline Sociais & $\begin{array}{l}\text { Capacidade de utilizar todos os seus conhecimentos - obtidos através de fontes, } \\
\text { meios e recursos diferenciados - nas diversas situações encontradas no mundo } \\
\text { do trabalho; isto é, da capacidade de transferir conhecimentos da vida cotidiana } \\
\text { para o ambiente de trabalho e vice-versa. }\end{array}$ \\
\hline Comportamentais & $\begin{array}{l}\text { Iniciativa, criatividade, vontade de aprender, abertura às mudanças, consciência } \\
\text { da qualidade e das implicações éticas do seu trabalho, o que envolve subjetividade } \\
\text { do indivíduo na organização do trabalho. }\end{array}$ \\
\hline Políticas & $\begin{array}{l}\text { Compreender sua posição e função na estrutura produtiva, seus direitos e deveres } \\
\text { como trabalhador, sua necessidade de participação nos processos de organização } \\
\text { do trabalho e de acesso e domínio das informações relativas às reestruturações } \\
\text { produtivas e organizacionais em curso, assim como na esfera pública, nas institui- } \\
\text { ções da sociedade civil, constituindo-se como atores sociais dotados de interesses } \\
\text { próprios que se tornam interlocutores legítimos e reconhecidos. }\end{array}$ \\
\hline
\end{tabular}

Fonte: elaborado e adaptado de Deluiz (2004) $)^{28}$ 
No entanto, a autora enfatiza que mais importante do que possuir saberes disciplinares escolares ou técnico-profissionais, é a capacidade de mobilizá-los para resolver problemas e enfrentar os desafios na situação de trabalho.

Considerando a docência na Educação a Distância, Belloni ${ }^{29}$ ressalta que o professor-tutor deve ser "parceiro dos estudantes, no processo de construção do conbecimento; isto é, em atividades de pesquisa e na busca da inovação pedagógica". A autora apresenta três dimensões para a prática docente: (a) pedagógica, que envolve atividades de orientação, aconselhamento e tutoria, além de conhecimentos inerentes ao campo da Pedagogia; (b) tecnológica, que permite o estabelecimento de relações entre as tecnologias e a Educação, envolvendo a produção, avaliação, seleção e definição de estratégias para o uso de materiais pedagógicos; e (c) didática, relativa à formação específica do professor em determinados campos científicos e que requer atualização permanente. Ainda segundo a autora, o professor-tutor a distância deve ser plurivalente; desempenhar outros papéis: professor-conceptor (também chamado professor-conteudista, professor-autor); tecnólogo educacional (designerinstrucional) e monitor (suporte técnico). Nessa perspectiva, pode-se pensar a docência online de forma ampla, envolvendo, além dos saberes e prática que caracterizam o fazer pedagógico, as fases anteriores à implementação de um curso (análise/planejamento, design e desenvolvimento), e seu gerenciamento e avaliação. Ressalta a autora que é nesse momento que se dá a "transformação do professor de uma entidade individual para uma entidade coletiva"30, ainda que, na EAD, a docência se concretize, em geral, com o apoio de um conjunto de especialistas, todos visando a um objetivo comum: planejar e implementar o processo ensinoaprendizagem de forma efetiva.

Tractemberg e Tractemberg ${ }^{31}$ corroboram essa posição, admitindo que, em face da disseminação e acessibilidade das TIC, das redes e dos conhecimentos, "um único profissional dotado de competências adequadas pode planejar, desenvolver, divulgar e implementar seus próprios projetos de EAD".

Em seus estudos sobre docência, Tardif ${ }^{32}$ utilizou a expressão 'saberes docentes' em lugar de competências para enfatizar que o saber do professor é plural e estratégico, e compreende algumas dimensões que intervêm em sua prática. Afirma que esses saberes têm diferentes origens e identifica o saber profissional; o disciplinar; o curricular, e o da experiência (núcleo do saber docente), capaz de conferir aos professores o reconhecimento da sociedade e da comunidade científica. Da mesma forma, o autor analisa as relações que se estabelecem entre o corpo docente e esses mesmos saberes.

Para Villardi e Oliveira ${ }^{33}$, o tutor, a quem denominam 'professor invisível', necessita das qualidades propostas por Tardif, especialmente as da formação profissional e disciplinar. Da mesma forma é fundamental a adesão, a autonomia e a autoconsciência (os "três A" de Nóvoa), e as competências para ensinar identificadas por Perrenoud, com destaque para as referentes à organização, administração e avaliação das situações de aprendizagem.

Às dimensões apontadas por Belloni, as autoras acrescentam outra, a lingüistica - importante na passagem do discurso oral (presencial) para o escrito, próprio da EAD, além da dimensão pessoal, que equivale aos saberes experenciais de Tardif; ou seja, à prática educativa.

Ressalte-se que, qualquer que seja a proposta considerada, todas apontam para uma formação ampla e integrada do professor, que vai muito além da informação e do conhecimento, e incorpora outros tipos de saberes.

As competências/saberes docentes aqui apresentados não se esgotam nos autores mencionados, dado que a noção de competência é altamente polissêmica. Segundo Deluiz,

[...] esta polissemia tem origem nas diferentes visões teóricas que se fundamentam em matrizes epistemológicas diversas e que expressam interesses, expectativas e aspirações dos diferentes sujeitos coletivos, que possuem propostas e estratégias sociais diversas e objetivam a hegemonia de seus projetos políticos. ${ }^{34}$

Assim, outras competências podem ser acrescidas, como por exemplo, as relativas às dimensões político-sociais e éticas. Independentemente do significado dado ao termo, o desenvolvimento das competências particulares ou especializadas e da capacidade de tomar decisões e resolver problemas depende do pleno desenvolvimento da inteligência geral (MORIN). ${ }^{35}$

\section{SABERES E COMPETÊNCIAS DO PROFESSOR - ABORDAGEM PRÁTICA}

De acordo com Fleury e Fleury ${ }^{36}$, os conhecimentos e habilidades inerentes a um indivíduo possuem valor transitório, dado que as tecnologias organizacionais são dinâmicas e impõem, constantemente, novas necessidades de qualificação. Isso significa 
as competências necessárias

a uma determinada função

\section{variam de instituição}

para instituição, dai a

importância de se definirem

as competências necessárias

a cada função e o quanto

de cada competência é

requerida pela organização,

em consonância com a sua

missão, visão, valores e

estratégias.

$\bullet \bullet \bullet$

que uma competência válida para um contexto organizacional, em um determinado momento, pode tornar-se obsoleta, em razão da inserção de novas tecnologias no ambiente de trabalho ou em função de uma reorientação estratégica da organização.

Como, então, as organizações devem se preparar para as inovações que se fazem necessárias? É possível enfrentar um mercado altamente competitivo e globalizado tendo como referência apenas o conhecimento adquirido por meio da experiência? Como garantir vantagem competitiva e agregar valor aos seus produtos e serviços?

Para responder a essas questões, as organizações têm incorporado novas formas de aprender e de se relacionar com o conhecimento em suas práticas diárias. Considerando que o conhecimento e o compartilhamento de experiências são construídos nas relações interpessoais e nas atividades cotidianas (comunidades de prática), cresce, a cada dia, a necessidade de as organizações identificarem e mapearem as competências essenciais ao seu negócio e ao exercício de cada função, levando em conta também o potencial das pessoas que nelas atuam. Emerge daí a importância de que tais competências sejam identificadas no contexto das atividades profissionais, dado que a capacidade de produzir resultados é derivada do conhecimento aplicado, fundamentado em processos de ação-reflexão-depuração, o que ressalta o papel das competências individuais como fator de vantagem competitiva.
Muitos são os modelos teóricos que sugerem grupos de competências (conhecimentos, habilidades e comportamentos) desejáveis a uma boa atuação profissional. Entretanto, defende-se, neste artigo, que o melhor modelo é aquele que reflete a cultura vigente na organização; ou seja, o que se alinha às competências organizacionais.

Rabaglio $^{37}$ afirma que é possível identificar e mensurar competências mediante o uso de indicadores de comportamento, dado que este consiste em atividade passível de observação, com reflexos no ambiente. Assim, a autora argumenta que se pode, no mínimo, classificar um comportamento como adequado ou não e, de um modo geral, determinar que aspectos podem ser melhorados e quanto.

Cada vez mais presente em publicações, palestras e cursos diversos, a questão dos indicadores tem invadido o cotidiano das políticas econômicas e sociais, refletindo-se, por exemplo, no Produto Interno Bruto (PIB), na taxa de crescimento, no volume de negócios fechados, na balança comercial, na flutuação do dólar ou no nível de glicose de um paciente.

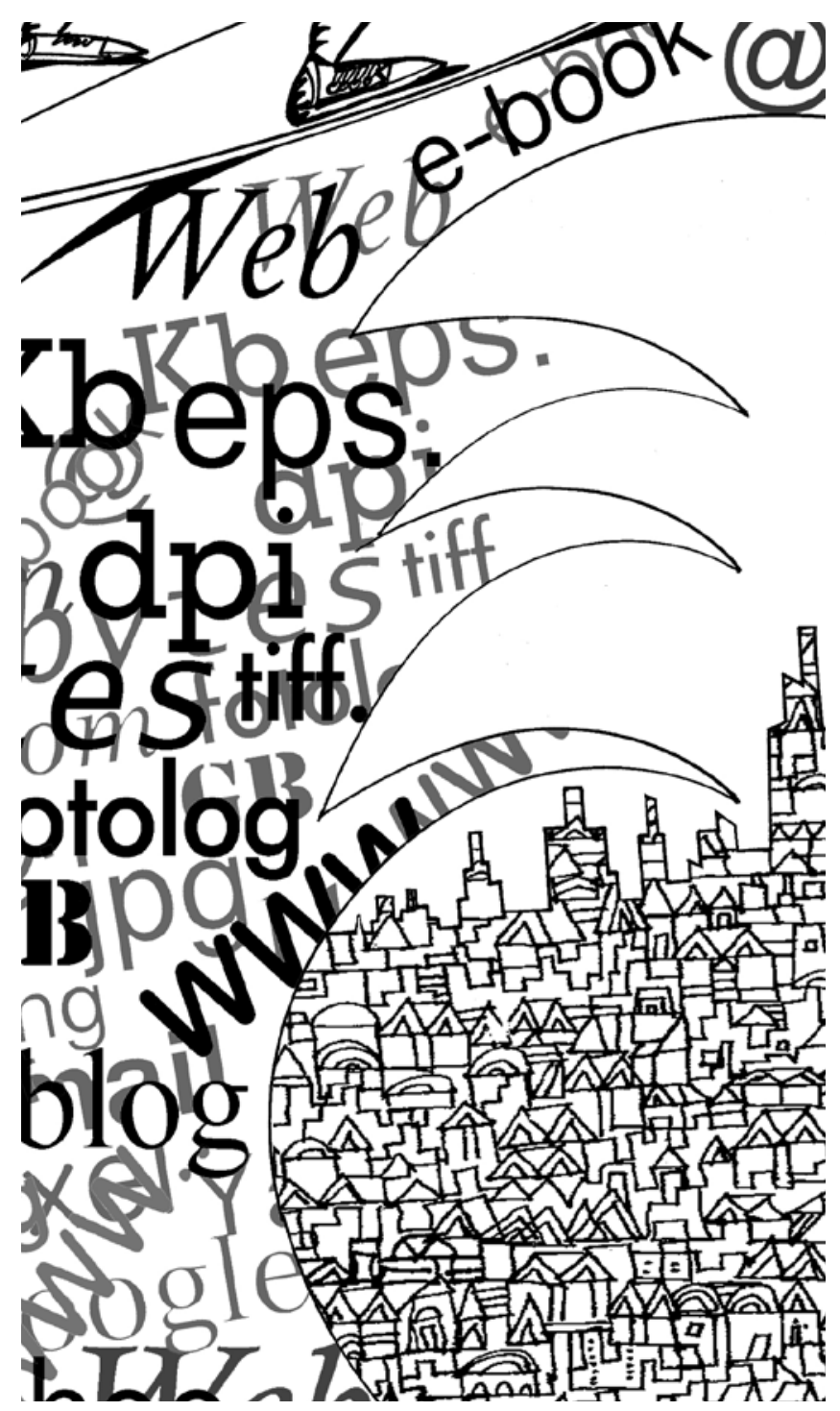


Para Takashina e Flores,

indicadores são formas de representação quantificáveis das características de produtos e processos, utilizados pelas organizações para controlar e melhorar a qualidade e o desempenho dos seus produtos e processos ao longo do tempo [...] são essenciais ao planejamento de metas quantificadas e o seu desdobramento na organização, e essenciais ao controle, porque os resultados apresentados através dos indicadores são fundamentais para a análise crítica do desempenho da organização, para as tomadas de decisões e para o replanejamento. ${ }^{38}$

É interessante notar, no entanto, que o conceito de indicadores, de um autor para outro, sofre poucas variações, e as idéias de medida, qualidade e quantidade estão sempre presentes, como se pode constatar nas definições, a seguir: (a) "especificação quantitativa e qualitativa para medir o atingimento de um objetivo',39; (b) "[...] valor calculado a partir dos parâmetros, fornecendo indicaşões sobre ou descrevendo o estado de um fenómeno, do meio ambiente ou de uma zona geográfica, de uma amplitude superior às informações directamente ligadas ao valor de um parâmetro"*0; (c) "expressão numérica, simbólica ou verbal, empregada para caracterizar as atividades (eventos, objetos, pessoas), em termos quantitativos e qualitativos, com o objetivo de determinar o valor". 41

Assim, pode-se concluir que indicadores são ferramentas de mensuração, utilizadas para o levantamento de aspectos quantitativos (medida) e/ou qualitativos (verificação do alcance dos objetivos pretendidos ou das mudanças propostas) de um dado fenômeno, com vistas a sua avaliação ou apoio a decisões.

Ao se referir aos indicadores de qualidade, Tironi afirma que:

[...] definir indicadores de qualidade é, basicamente, construir conceitos que permitam a sua mensuração, providência indispensável para a avaliação dos resultados alcançados com os esforços aplicados na melhoria da qualidade, ou para traçarem-se comparações entre produtos e serviços a partir da qualidade. ${ }^{42}$

Alerta-se, no entanto, que a geração de indicadores deve ser realizada criteriosamente, tendo em vista garantir a disponibilidade de dados e resultados mais relevantes, no menor prazo possível e ao menor custo. Assim, critérios, como seletividade ou importância, acessibilidade, abrangência, comparabilidade, baixo custo de obtenção, entre outros, devem ser observados, tendo em vista nortear essa geração (TIRONI) ${ }^{43}$

Reitera-se que, muito embora o mapeamento, a mensuração e a avaliação com foco em competências não seja tarefa das mais simples, é possível fazê-lo, por meio de indicadores de comportamento. Por exemplo, ser gentil com os colegas de trabalho; estimular a apresentação de idéias ou saber ouvir feedback são indicadores que denotam competência interpessoal. Assim, essa identificação possibilita estabelecer o ponto de deficiência de cada profissional e traçar um plano de ação para a melhoria daquele indicador e de seu nível de competência, com vistas à redução do gap observado e aumento de sua eficiência.

Finalmente, outro aspecto a ser considerado é que as competências necessárias a uma determinada função variam de instituição para instituição, daí a importância de se definirem as competências necessárias a cada função e o quanto de cada competência é requerida pela organização, em consonância com a sua missão, visão, valores e estratégias.

\section{ConClusão}

A era da informação e do conhecimento, que caracteriza os dias atuais, confere à educação um papel de relevo na formação para a vida em sociedade e para o trabalho. Formar indivíduos para um mundo globalizado, marcado por rápidas mudanças e imerso numa cultura digital, requer novas formas de pensar, de produzir e de divulgar o conhecimento por parte dos atores educacionais. Tendo essas considerações como "pano de fundo", buscou-se, neste artigo, refletir sobre a importância do desenvolvimento de competências para que o professor possa atuar no contexto em tela, tendo em vista uma prática educacional que cumpra sua função social, considerando a tecnologia como parte integrante do processo ensino-aprendizagem. Foi também objetivo deste trabalho ressaltar a necessidade de se identificar e mapear as competências profissionais que o docente deve desenvolver, em consonância com as estratégias da organização onde atua.

Educar na cibercultura implica docência interativa, presencial ou online, e pressupõe participação colaborativa, intervenção na mensagem, bidirecionalidade e dialogicidade e, ainda, conexões em teias abertas de relacionamentos. Isso requer não apenas abertura para as mudanças, mas também redimensionamento das competências e solidez acadêmica com vistas à autonomia profissional. Tais competências/saberes devem estar relacionados a diferentes dimensões, sejam elas profissionais, didáticas, pesso- 
ais, sociais, lingüísticas, éticas, políticas, pedagógicas. Devem, fundamentalmente, preparar o sujeito para enfrentar os desafios da vida, e não para as circunstâncias do momento.

A escola, por sua vez, para receber esse novo docente, deve redefinir o seu papel. Como núcleo de aquisição do conhecimento, para o qual convergem as dimensões do ser, da cultura e do poder, deve valorizar seus profissionais, adotando um modelo pedagógico que considere os indivíduos como centro de sua ação, enfatizando a didática crítica, dando espaço à reflexão sobre a prática pedagógica e propondo a pesquisaação. Em síntese, deve transformar-se em uma organização que aprende, dialogando criticamente com as demandas da pós-modernidade.

Ao professor cabe avaliar o seu fazer pedagógico, a fim de diagnosticar o seu nível de competências; transformar o discurso educacional em prática (não adianta falar de interação, dialogicidade e avaliação mediadora e ter o espírito impregnado de tabuada e caligrafia); substituir a 'Pedagogia da transmissão' pela Pedagogia que conduza à autonomia e à emancipação; estimular o pensamento reflexivo e crítico em detrimento da memorização e reprodução automática de conhecimentos; priorizar a avaliação qualitativa para observar e acompanhar o desempenho do aluno; intervir de forma sistemática e individualizada, ajustando as situações didáticas às necessidades da turma. Tais ações dependem de contínua atualização, que garanta tanto o fortalecimento de suas competências intelectuais e técnicas como daquelas de natureza organizacional ou metódica, comunicativa, comportamental e político-social. Cabe reiterar que as competências necessárias a uma determinada função variam de instituição para instituição. Por isso, a importância de um alinhamento à realidade organizacional em que o professor exerce suas atividades, bem como de sua vinculação aos objetivos educacionais de formação humana e aos processos metodológicos e organizacionais de apropriação e construção de saberes e modos de atuação.

A imprevisibilidade e a incerteza do devir que caracterizam os dias atuais não podem ser fatores de paralisia; ao contrário, devem constituir-se em permanente desafio. É preciso antever as mudanças, compreendê-las e agir sobre elas, abandonando velhas práticas educativas que já não respondem às exigências da contemporaneidade. No atendimento às novas demandas, é necessário que o professor reflita sobre sua ação educativa e as competências requeridas a sua atuação e, olhando para o futuro, não perca a capacidade de ousar.

\section{Notas:}

LÉVY, P.. A revolução contemporânea em matéria de comunicação. In: MARTINS, F. M.; SILVA, J. M. da. Para navegar no século XXI: tecnologias do imaginário e cibercultura. Porto Alegre : Sulina-Edipucrs, 2000. p. 195-216.

2 SOARES, S. G.. Inovações no ensino superior reflexões sobre a educação a distância. In: CASTANHO, S.; CASTANHO, M. E. L. M. (Orgs). O que há de novo na educação superior: do projeto pedagógico à prática transformadora. Campinas : Papirus, 2000.

3 FLEURY, A.; FLEURY, M. C. Construindo o conceito de competências. Revista de Administração Contemporânea, v. 5, p. 183-196, 2001. Edição Especial

4 QUÉAU, Philippe. A revolução da informação: em busca do bem comum. Informe Brasília, v.27, n. 2, maio/ago., p. 198-205, 1998.

5 SCHULTZ, T. W.. O capital humano: investimentos em educação e pesquisa. Rio de Janeiro : Zahar, 1973.

6 McLUHAN, M.. Os meios de comunicação como extensão do homem. São Paulo : Cultrix, 1964. p. 37.

SANTOS, L. L. C. P.. Formação do professor e pedagogia crítica. In: FAZENDA, Ivani (Org). A pesquisa em educação e as transformações do conhecimento. Campinas: Papirus, 1998. p. 127.

8 FALSARELLA, A. M.. Formação continuada e prática de sala de aula: os efeitos da formação continuada na atuação do professor. Campinas : Autores Associados Ltda., 2004. v.1.

9 NÓVOA, A.. Diz-me como ensinas, dir-te-ei quem és, e vice-versa. In: ACTAS do Profma. Lisboa: Faculdade de Psicologia e de Ciências da Educação, 1991. p. $1-20$.

${ }^{10}$ PORTO, Y. S. da. Formação continuada: a prática pedagógica recorrente. In: MARIN, Junqueira Alda (Org.). Educação continuada: reflexões alternativas. Campinas : Papirus, 2000.

${ }^{11}$ Id. ibid.

${ }^{12}$ DEWEY, J.. How we think. London : Heath, 1933.

${ }^{13}$ SHÖN, D. A.. Educando o profissional reflexivo, um novo design para o ensino e a aprendizagem. Porto Alegre: Artmed, 2000.

${ }^{14}$ HARGREAVES, A.. O ensino da sociedade do conhecimento: educação na era da insegurança. Porto Alegre : Artmed, 2004. p. 34.

${ }^{15}$ MEISTER, J. C.. Educação corporativa: a gestão do capital intelectual através das universidades corporativas. São Paulo : Mackron Books, 1999.

${ }^{16}$ SENGE, P. M. A quinta disciplina: arte e prática da organização que aprende. 16. ed.. São Paulo : Best Seller, 2004. p. 37.

${ }^{17}$ BONILAURI, A. R. C. Educação corporativa: reflexões sobre sua razão de ser e seus limites. In: FERREIRA, José Rincon; BENETTI, Gilberto et al. O futuro da indústria: educação corporativa - reflexões e práticas. Brasília: IEL, 2006. p. 89. (Política Industrial, Tecnológica e de Comércio Exterior, 13).

${ }^{18}$ SOARES, S. G..(2000), op. cit.

19 "Filhos da idade digital, de uma revolução das comunicações que está a moldar uma nova geração e o seu mundo, um fenômeno jamais visto". TAPSCOT'T, D.. Nova geração de consumidores. Adaptado por Jorge Nascimento Rodrigues. Disponível em: <http://www. janelaweb.com/geração/dtlivro.html $\geq$, Acesso em: 11/10/2006. p. 2.

${ }^{20}$ TAKAHASHI, T.. Sociedade da informação no Brasil. In: TAKAHASHI, Tadao (Org.). Livro verde. Brasília : Ministério da Ciência e Tecnologia, 2000.

${ }^{21}$ SILVA, M.. Indicadores de interatividade para o professor presencial e on-line. Revista DiálogoEducacional, Curitiba, v. 4, n. 12, maio/ago. 2004. p. 93-109. Disponível em: $\leq$ http://www2.pucpr.br/multimidia/mestr_educacao/n 12/ artigo7.pdf > . Acesso em: 22/09/2006. 
22 CÁCERES, N. D. M. La formación docente....abriendo caminos. In: CALDERARO, Maria da Assunção; LOPES, Paulo R. C. Formação de professores no mundo contemporâneo. Juiz de Fora (MG) : UFJF, 2006. p. 39-40.

23 SILVA, M.. (2004), op. cit., p. 24.

24 NÒVOA, A.. Vida de professores. Lisboa: Porto, 1995.

25 Id. ibid., p. 7

26 PERRENOUD, P.. Dez novas competências para ensinar. Porto Alegre : Artes Médicas, 2000. p. 16.

27 DELUIZ, N.. A globalização econômica e os desafios à formação profissional. Boletim Técnico do SENAC, Rio de Janeiro, v. 30, no. 3, p. 73-79, set./ dez., 2004.

28 Id. ibid., 2004.

29 BELLONI, M. L. Educação a distância. Campinas : Ed. Associados, 2001. p. 81.

${ }^{30}$ Id. ibid., p. 74.

31 TRACTENBERG, L.; TRACTENBERG, R.. Seis competências essenciais da docência online independente. Disponível em: swww.livredocencia.com. br $>$, Acesso em: 16/07/2007. p. 3.

32 TARDIF, M.. Saberes docentes e formação profissional. Petrópolis(RJ) : Vozes, 2002.

33 VILLARDI, Raquel; OLIVEIRA, Eloisa Gomes de. Tecnologia na educação: uma perspectiva sócio-interacionista. Rio de Janeiro : Dunya, 2005. p. 116.

34 DELUIZ, N.. O modelo das competências profissionais no mundo do trabalho e na educação: implicações para o currículo.Boletim Técnico do Senac, Rio de Janeiro, v. 27, no 3, set./dez.2001. Disponível em: $\leq$ http:// www.senac.br/INFORMATIVO/BTS/273/boltec273b.htm $>$, Acesso em: 04/10/2006. p. 9.

35 MORIN, E.. A cabeça bem feita: repensar a reforma, reformar o pensamento. Rio de Janeiro : Bertand-Brasil.

36 FLEURY, A.; FLEURY, M. C. (2001), op. cit.

37 RABAGLIO, M. O. Ferramentas de avaliação de performance com foco em competências. Rio de Janeiro : Qualitymark, 2006.

38 TAKASHINA, N. T.; FLORES, M. C. X.. Indicadores da qualidade e do desempenho: como estabelecer metas e medir resultados. Rio de Janeiro : Qualitymark, 1995. p. 4-19.

39 FINEP. Termos e conceitos. Rio de Janeiro, 2002. Disponível em: $\leq$ www. finep.gov.br $>$, p. 11 . Acesso em: 22/09/2007.

40 ORGANISATION DE COOPÉRATION ET DE DÉVELOPPEMENT ÉCONOMIQUES OCDE. Glossary of Statistical Terms. Genebra: OCDE, 2001. Disponível em: $\leq$ http://cs3-hq.oecd.org/scripts/stats/glossary/detail. asp.> Acesso em: 22/09/2007. p. 191.

41 INTERNATIONAL FOR ORGANIZATION STANDARDIZATION. ISO 11620:1998 (F): Information et Documentation - Indicateurs de performance des bibliothèques. Genebra : ISO, 1998. p. 3.

42 TIRONI, L. F. et al.. Critérios para geração de indicadores de qualidade e produtividade no serviço público. Rio de Janeiro : MEFP/Ipea. 1991. (Texto para discussão, 238) p. 8.

43 TIRONI, L. F. et al..(1991), op. cit..

\section{ABSTRACT}

Mirian Maia do Amaral; Lúcia Regina Goulart Vilarinho. Surfing the information and knowledge society: the issue of teachers' competences.

This article emphasizes the challenge of education in cyberculture, where students are the focus of educational action and the teacher is one of the many information sources they resort to. In order to meet educational demands, teachers need ongoing updating of their knowledge and this implies mastering knowledges/competences needed in teaching. This will ensure a proficient action capable of facing the challenges imposed by a society marked by uncertainty, instantaneous communication, and rapid change. Hence, the need to identify and map out teachers' competences, whose repertoire must be tuned to the context and strategies of the institutions where these actors develop their work.

Keywords: Information Society; Cyberculture; Competences; Teacher; Interaction; Professor; Student.

\section{RESUMEN}

Mirian Maia do Amaral; Lúcia Regina Goulart Vilarinho. Navegar en la sociedad de la información y del conocimiento: la cuestión de las capacidades docentes.

El artículo enfatiza el desafio de educar en la cibercultura en un momento en que los alumnos constituyen el centro de la acción educativa, y el profesor una de las muchas fuentes de información a la que ellos recurren. Este profesor, para poder responder a las demandas educacionales, tiene que actualizarse constantemente, lo que implica el dominio de un conjunto de conocimientos/ capacidades que son necesarios para el ejercicio de la docencia, con el fin de garantizar una actuación proficiente, capaz de enfrentar los desafios impuestos por una sociedad marcada por la incertidumbre, la instantaneidad y la rapidez de los cambios. Se desprende de esto la necesidad de identificar y mapear las capacidades docentes, cuyo repertorio debe estar en concordancia con el contexto y las estrategias de la institución donde este actor ejerce sus actividades.

Palabras clave: Sociedad de la Información; Cibercultura; Capacidad; Docente; Interacción; Profesor; Alumno. 